\title{
REPARO A QUENTE NOS COLETORES DE GASES DE COMBUSTÃO ATRAVÉS DA PROJEÇÃO DE MASSA REFRATÁRIA COM VIDEO MONITORAMENTO*
}

\section{Resumo}

Neussias Inocêncio Henrique ${ }^{1}$ Giovani Fonseca ${ }^{2}$ Sandro Azevedo 3 Brian Willians ${ }^{4}$

Robson Jacinto Coelho ${ }^{5}$

Charles Humberto ${ }^{6}$

Raphael Miranda ${ }^{7}$

O processo de coqueificação em uma Coqueria do tipo Heat Recovery é baseado na queima da matéria volátil presente no carvão, principal combustível para aquecimento dos fornos. A Combustão dos gases tem que ocorre dentro da câmara primaria (interior do forno) e na câmara secundaria (Sole Flue). Devido a algumas interferências no processo de coqueificação não ocorre a queima completa dos gases no forno e com isso a combustão terciária ocorre nos coletores de gases (equipamento destinado apenas para transporte dos gases de combustão). Com a queima dos gases nos coletores temos o aumento de temperatura no interior do duto e como a estrutura refratária não foi projetada para suportar esse limite máximo de temperatura acontece a contração e posteriormente colapso do refratário causando perdas em todo o processo. Os principais benefícios após a aplicação dessa técnica é a redução no tempo de reparo, aumento do rendimento de aplicação da massa refratária e prolongamento na vida útil desse equipamento.

Palavras-chave:Coqueria Heat Recovery; Combustão; Refratário; Controle por PID.

\section{Abstract}

REPAIR IN HOT CONDITION OF THE GASES' COLLECTORS THROUGH PROJECTION OF REFRACTORY MASS USING VIDEO MONITORING

In the heat-recovery cokemaking process, the complete gas produced from coal carbonization is combusted directly inside the coke oven, thus creating the heat needed for carbonization. The burning of the volatiles has to occur in the primary chamber (internal oven) and in the secondary chamber (sole flue). Due to interferences on the coking process, the gas is not completed burned in the furnaces; hence its complete burning occurs in the gas ducts (equipment designed only to transport combustion gases). Due to the burning of the gases in the ducts, the temperature inside the collector rises above the limit it was originally designed to support, therefore the refractory structure shrink and consequently collapses causing losses to the process.

The main benefits gained after the performance of this technique are; reduction on the repairing time, increase on the performance of the refractory mass application and extension of the life cycle of the equipment.

Keywords: Heat Recovery Coke Plant, Combustion, Refractory and PID Controller.

1 Engenharia Química, Engenheiro de Processo Junior, thyssenkrupp CSA, Rio de Janeiro, RJ, Brasil.

2 Engenheiro Mecânico, Técnico Especialista Refratário, thyssenkrupp CSA, Rio de Janeiro, RJ, Brasil.

3 Técnico em Eletromecânico, Técnico Especialista Refratário, thyssenkrupp CSA, Rio de Janeiro, RJ, Brasil..

4 Engenheiro Civil, Especialista Refratário, thyssenkrupp CSA, Rio de Janeiro, RJ, Brasil.

5 Engenharia Metalúrgica, Mestrado em Engenharia de Materiais, Engenheiro Especialista em Redução, thyssenkrupp CSA, Rio de Janeiro, RJ, Brasil.

6 Tecnólogo em Mecânica, Coordenador Preservação Bateria Coqueria, thyssenkrupp CSA, Rio de Janeiro, RJ, Brasil.

7 Engenharia Química, Analista de Operações Pleno, thyssenkrupp CSA, Rio de Janeiro, RJ, Brasil. 


\section{INTRODUÇÃO}

A Coqueria da thyssenkrupp CSA utiliza a tecnologia Heat Recovery para produção de coque e de vapor como subproduto do processo. A matéria volátil presente no carvão é utilizada como combustível para aquecimentos dos fornos. $O$ ar necessário para ocorrer à combustão é succionado da atmosfera através de exaustores fazendo o processo trabalhar com pressão negativa.

Os fornos como mostra a Figura 1, possuem as seguintes dimensões, 13,3 metros de comprimento, 3,6 metros de largura e 2,4 metros de altura. $O$ forno é dividido em duas câmaras de combustão, primária e secundária (topo e soleira respectivamente). O topo é composto por seis entradas de ar e a soleira composta por dezesseis entradas de ar.

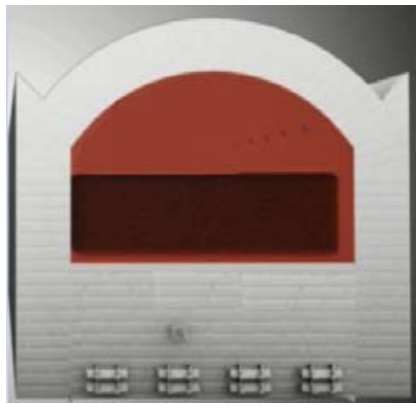

Figura 1. Modelo do forno

O processo de queima da matéria volátil ocorre em duas etapas. Primeiramente o ar succionado no topo dos fornos reage com os gases provenientes da massa de carvão enfornada, nessa etapa ocorre à queima de aproximadamente $60 \%$ dos gases. Os gases remanescentes são succionados para a soleira pelos Donw Comers. Na soleira o ar é distribuído nos 16 pontos onde ocorre a queima secundária (remanescente). Após os gases percorrerem toda a extensão da soleira e serem queimados, os fumos são enviados aos coletores via Up Takes. A Figura 2 exemplifica o processo de queima nos fornos.

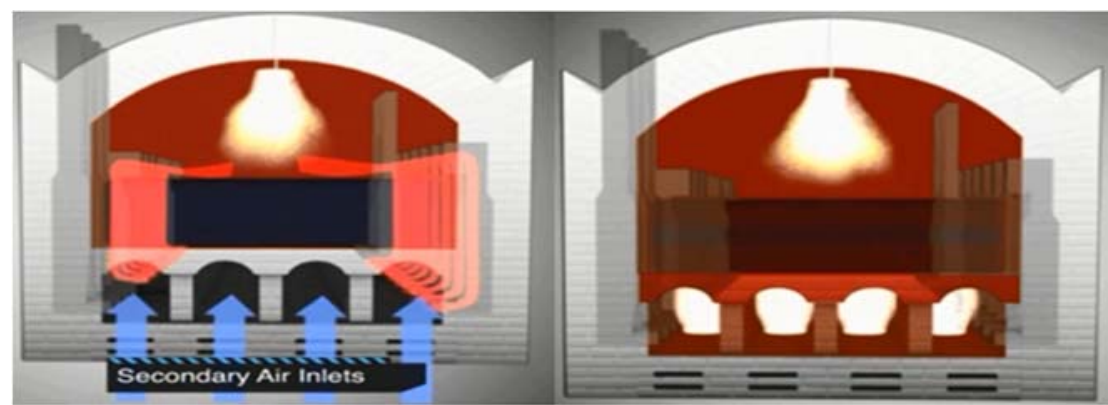

Figura 2. Exemplificação da combustão no topo e soleira

O coletor tem como objetivo transportar os gases queimados durante a combustão até as caldeiras onde a energia térmica será utilizada para a produção de vapor. Após essa etapa existe o processo de dessulfuração FGD (Full Gas Desulfurization) para limpeza dos gases antes de ser enviada a chaminé. 


\section{INFLUÊNCIAS NO PROCESSO HEAT RECOVERY}

\# \#

A temperatura dos fornos deve ser mantida dentro da faixa ótima de operação para maximizar o processo de coqueificação.

Durante o processo de coqueificação a queima da matéria volátil, principal combustível do forno, sofre influência de vários parâmetros externos que afetam diretamente a temperatura dos fornos, sendo os principais mostrados na Tabela 1.

Tabela 1. Parâmetros externos que influenciam o processo de coqueificação.

\begin{tabular}{|c|c|c|}
\hline \multicolumn{3}{|c|}{ INFLUÊNCIAS NO PROCESSO HEAT RECOVERY } \\
\hline Matéria Prima & Estrutura dos Fornos & Controle de Processo \\
\hline $\begin{array}{l}\text { - Matária Volátil } \\
\text { - Umidade da mistura de carvão } \\
\text { - Cinza }\end{array}$ & $\begin{array}{l}\text { - Projeto da soleira dos fornos } \\
\text { - Sistema de isolamento dos fornos } \\
\text { - Vedação das portas } \\
\text { - Quantidade e projeto das entradas de ar } \\
\text { - Qualidade do refratário }\end{array}$ & $\begin{array}{l}\text { - Temperatura no incío do enfornamento } \\
\text { - Altura da carga enfornada } \\
\text { - Densidade da massa enfornada } \\
\text { - Perda de calor } \\
\text { - Volume da câmara de combustão } \\
\text { - Cinza } \\
\text { - Pressão de succção dos gases } \\
\text { - Volume de ar para combustão } \\
\text { - Tempo de residência } \\
\text { - Entrada de ar falso } \\
\text { - Habilidade dos operadorees } \\
\text { - Disponiblidade de máquina }\end{array}$ \\
\hline
\end{tabular}

Esses parâmetros afetam a geração de gases dentro do forno e consequentemente a combustão que mantem o forno aquecido pode perder eficiência.

\subsection{LIBERAÇÃO DE GASES E QUEIMA NO FORNO}

\#

Logo após o enfornamento da massa de carvão, inicia-se o processo de coqueificação, com a liberação de gases proveniente da matéria volátil. A geração de gases tende a seguir a curva teórica, apresentada na Figura 3.

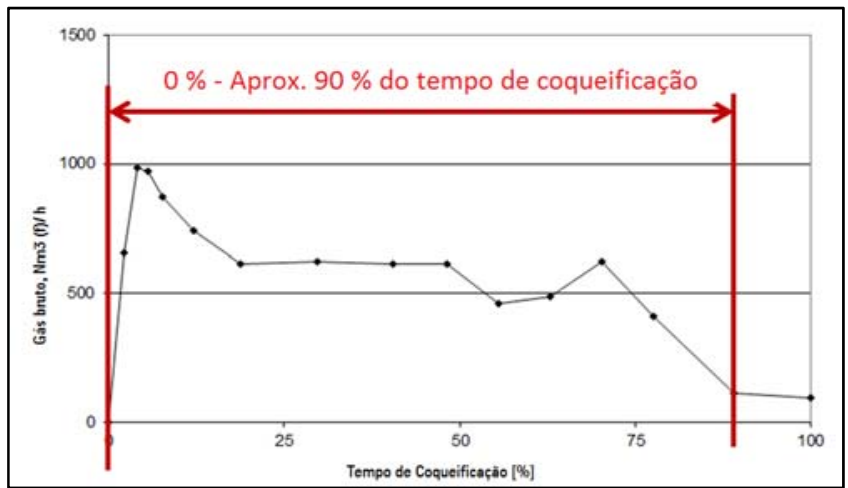

Figura 3. Geração de gases durante processo de coqueificação.

Com o objetivo de maximizar a queima e manter os fornos com a máxima temperatura possível durante o processo, a quantidade de ar succionado no forno deve acompanhar na mesma proporção às oscilações da geração.

Devido às influências que ocorrem no processo, a geração de gases tende a divergir da curva teórica, neste caso, o volume de ar succionado deve variar de acordo com a geração de gases real no forno. 
No inicio do processo necessitamos de uma grande quantidade de ar para ocorrer à completa combustão, após aproximadamente 10 horas o volume de gás gerado começa a diminuir fazendo com que o gás enviado a soleira seja menor, consequentemente a quantidade de ar na soleira não necessita ser máxima.

No final do processo de coqueificação, os gases gerados são queimados somente na câmara primária, sendo assim, a quantidade de ar succionado deve ser reduzida, pois caso ocorra excesso de ar o mesmo irá reagir com o próprio coque, reduzindo o volume de produção (Burn Loss). A figura abaixo representa o fluxo dos gases:

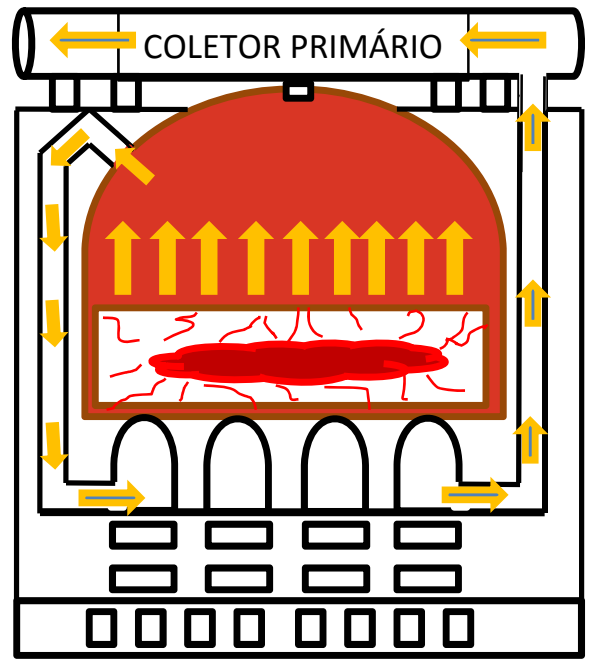

Figura 4. Fluxo dos gases durante processo de coqueificação.

\subsection{COMBUSTÃO TERCIARIA}

Uma vez que existe alguma interferência nas variáveis que influencia no processo de coqueificação, a queima dos gases no interior no forno (combustão primaria) e no sole flue (combustão secundaria) torne se incompleta, sendo assim os gases são queimados nos coletores de gases, onde não é para acontecer a combustão, sendo assim a temperatura no interior dos coletores excede 0 limite máximo de temperatura máximo da estrutura refratária.

Quando a temperatura no interior dos coletores excede o limite máximo de refratário as consequências é a parada no processo de enfornamenro/desenfornamento até que se atinja a temperatura ideal e nos casos mais graves ocorre o colapso da estrutura refratária dos coletores sendo necessário realizar reparo nos coletores e reduzir a carga de carvão enfornada para diminuir a liberação de material volátil por motivo de segurança para equipe que está realizando o reparo refratário.

\subsection{REFRATÁRIOS}

Materiais refratários, por definição, devem ser resistentes ao calor e são expostas a diferentes graus de estresse: tensão mecânica, estresse térmico e tensão, corrosão/erosão de sólidos, líquidos e gases, de difusão de gás e mecânica abrasão a várias temperaturas. Diferentes refratários são projetados e fabricado de modo a que as propriedades dos refratários são adequadas para suas aplicações.

Nos coletores de gases de combustão da Coqueria são utilizados refratários que apresentam características conforme a figura abaixo: 
Tabela 2. Características dos refratários dos coletores.

\begin{tabular}{|l|c:c|c|}
\cline { 2 - 4 } \multicolumn{1}{c|}{ Propriedades } & \multicolumn{3}{c|}{ Tipos } \\
\hline & $\begin{array}{c}\text { Tijolo dos } \\
\text { coletores de } \\
\text { gases } \\
\text { CXW-1.0 }\end{array}$ & $\begin{array}{c}\text { Tijolo dos } \\
\text { coletores de } \\
\text { gases } \\
\text { CX-1.0 }\end{array}$ & $\begin{array}{c}\text { Tijolo dos } \\
\text { coletores de } \\
\text { gases } \\
\text { CX-1.5 }\end{array}$ \\
\hline Densidade [g/cm^3] & 1.0 & 1.0 & 1.5 \\
\hline Resistencia a Frio [Mpa] & $\geq 2.9$ & $\geq 2.9$ & $\geq 5.0$ \\
\hline $\mathrm{Fe}_{2} \mathrm{O}_{3}[\%]$ & $\leq 1.0$ & $\leq 1.0$ & $\leq 1.0$ \\
\hline $\mathrm{Al}_{2} \mathrm{O}_{3}[\%]$ & $\geq 33$ & $\geq 48$ & $\geq 48$ \\
\hline Condutividade Térmica $[\mathrm{W} / \mathrm{mK}]$ & $\leq 0,35$ & $\leq 0,35$ & $\leq 0,40$ \\
\hline Máxima temperatura $\left[{ }^{\circ} \mathrm{C}\right]$ & 1350 & 1400 & 1400 \\
\hline
\end{tabular}

\subsection{PRINCIPAIS DANOS A ESTRUTURA REFRATARIAS INTERNA DOS DUTOS COLETORES DE GASES.}

Devido a uma constante variação de temperatura acima do limite do refratário a uma alteração na expansão e contração dos tijolos mudando sua composição química e física, esta seria uma das nossas causas, como consequência ocorre um colapso dos revestimentos refratários dos dutos, vindo a comprometer o revestimento metálico externo. Uma vez que ocorre a queda da estrutura refratária é necessário fazer a manutenção corretiva, aonde expõem a equipe a altas temperaturas. As figuras as seguir exemplifica a situação:
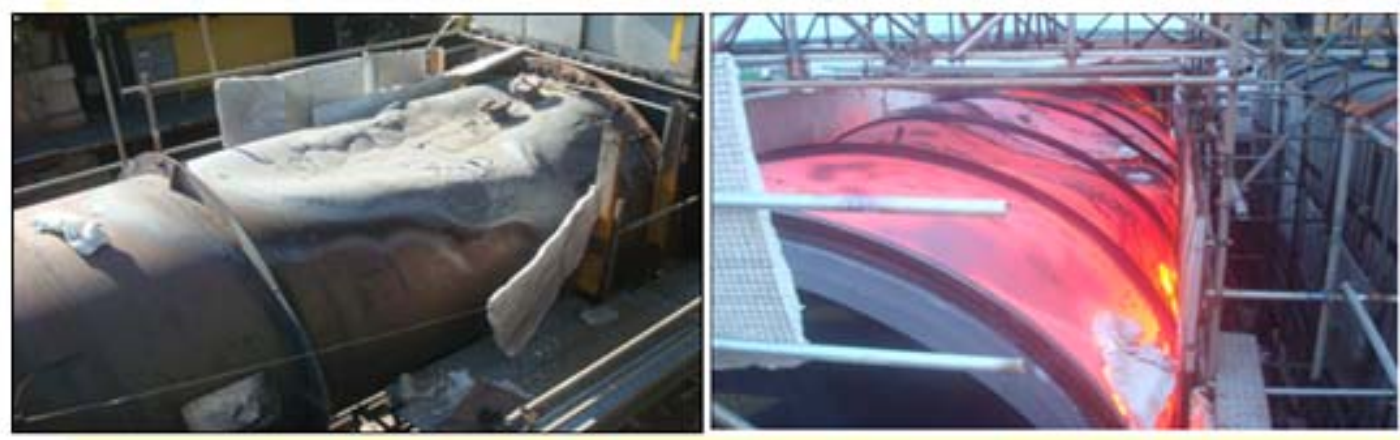

Figura 5. Coletores de gases com colapso da estrutura refratária.

Como a temperatura nos coletores de gases não pode exceder a temperatura limite (mínima e máxima) do refratário a manutenção é realizada sem que a produção de coque seja interrompida.

Com o objetivo de mitigar possíveis acidente a carga de carvão enfornada por forno é reduzida de $1000 \mathrm{~mm}$ de carvão para $900 \mathrm{~mm}$. Diante disso o volume de gás de combustão gerado que é encaminhado para as caldeiras torna se menor, sendo assim a temperatura média dos gases é reduzida para garantir uma melhor condição de trabalho. Porém, como é enfornada uma quantidade menor de carvão a produção de coque é menor nesses fornos, logo é necessário agilidade nos reparos para que os fornos voltem a produzir a quantidade nominal de projeto dos fornos 


\section{MATERIAIS E MÉTODOS}

Para isso foi desenvolvida pela equipe da preservação refratária técnicas e metodologias de trabalho que possibilita agilidade na manutenção dos dutos e coletores e evitando retrabalho, conforme o fluxo de trabalho abaixo:

Tabela 3. Fluxo de trabalho de reparo nos coletores.

\begin{tabular}{|c|c|}
\hline Etapas & Reparo nos coletores de gases \\
\hline 1 & Montagem de andaimes \\
\hline 2 & Corte da chapa metálica \\
\hline 3 & Remoção de isolamento \\
\hline 4 & Desmontagem dos tijolos \\
\hline 5 & Desmontagem e inserção de caixas \\
\hline 6 & Preparo da base \\
\hline 7 & Assentamento das fiadas de tijolos \\
\hline 8 & Aplicação de isolamento \\
\hline 9 & Reposionamento da chapa metálica \\
\hline 10 & Projeção de massa refratária \\
\hline
\end{tabular}

Após todas as etapas de reparo nos coletores de gases a equipe de preservação refratária identificou de inspecionar e se necessário realizar correções na parte interna dos coletores na região do reparo. Sendo assim foi desenvolvida a técnica de realizar a endoscopia e projeção de massa refratária semi-densa conforme as fotos abaixo:

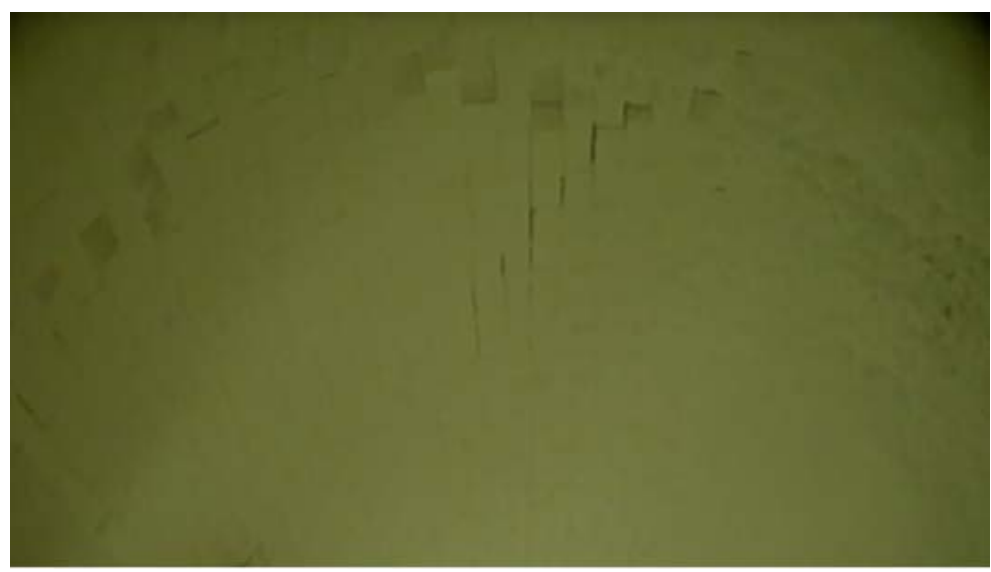

Figura 6. Ponto de junção do reparo refratário.

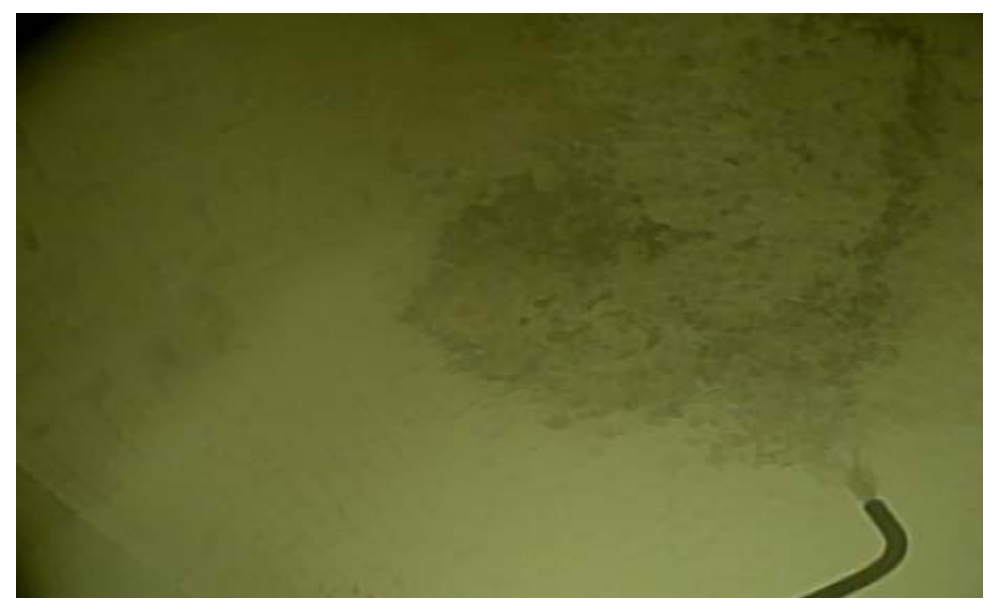


Figura 7. Projeção de massa refratária no ponto de junção do reparo refratário.
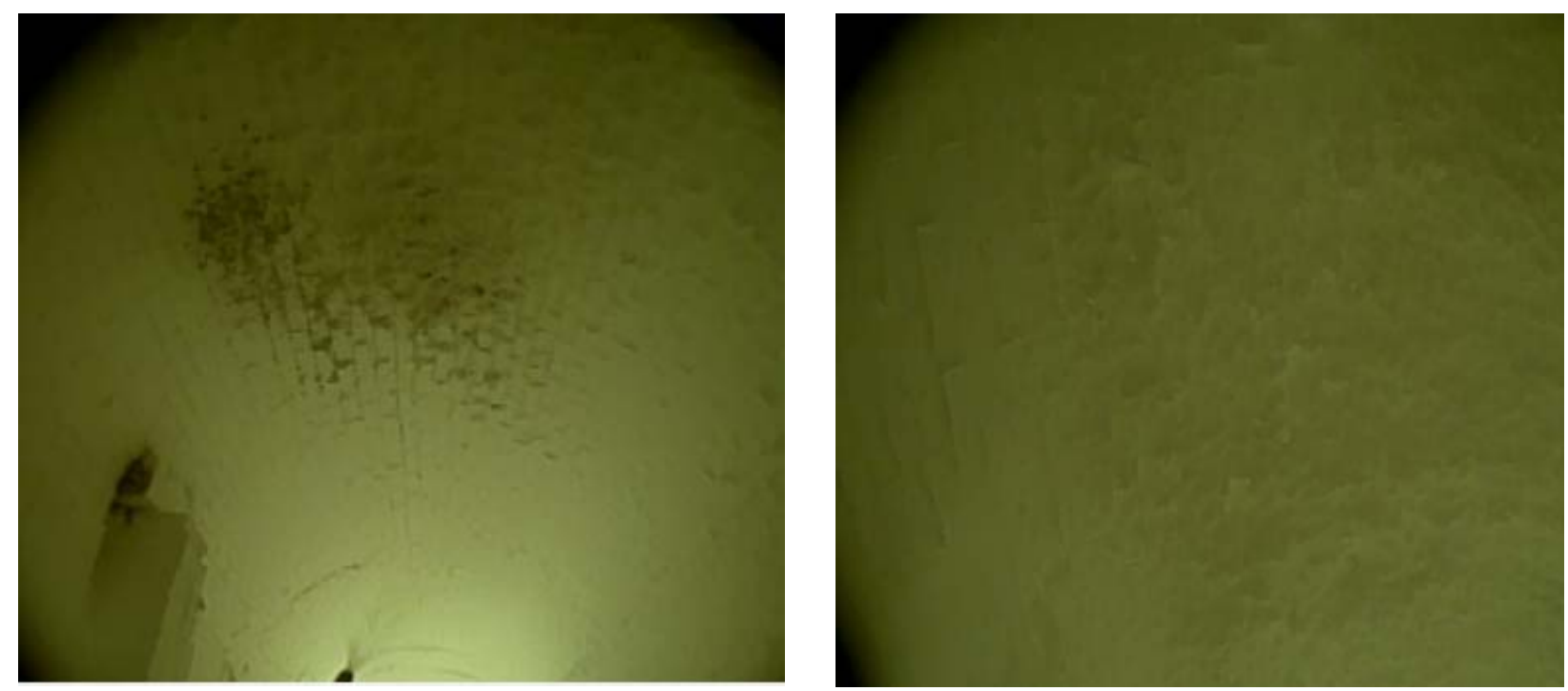

\section{CONCLUSÃO}

Figura 8. Projeção finalizada no ponto de reparo.

Com a utilização de vídeo monitoramento na ultima fase do processo de reparo nos coletores, projeção de massa refratária, foi possível identificar os possíveis pontos de falha e fazer as devidas correções no assentamento e amarração dos tijolos, além disso, tem se economia em material e tempo de projeção. Vale a pena ressaltar que todos o trabalho de reparo nos coletores são realizados a quente, ou seja, a uma temperatura média de $1000^{\circ} \mathrm{C}$ no interior dos coletores.

\section{REFERÊNCIAS}

1. POPOV, E. P. - Introdução à Mecânica dos Sólidos.

2. BEER, F. P. \& Johnson, E. R. - Resistência Dos Materiais

3. MELCONIAN, SARKIS. Mecânica Técnica e Resistência Dos Materiais. Editora Érica..

4. Coelho, Robson Jacinto. Modelos de previsão de qualidade metalúrgica do coque a partir da qualidade dos carvões individuais e do coque obtido no forno piloto de coqueificação da CST. Dissertação (Mestrado) - Universidade Federal de Ouro Preto. Rede Temática em Engenharia de Materiais, 2003.

5. Junqueira, Yan Samuel Ferreira. "Stamping Charger com automatismo" Compactação da MASSA DE CARVÕES - Estudo teórico e análise pratica na TKCSA. Contribuição técnica ao $44^{\circ}$ Seminário de Redução de Minério de Ferro e Matérias-primas, $15^{\circ}$ Simpósio Brasileiro de Minério de Ferro e $2^{\circ}$ Simpósio Brasileiro de Aglomeração de Minério de Ferro, 15 a 18 de setembro de 2014, Belo Horizonte, MG, Brasil.

6. L.D. Hart (ed.), Alumina Chemicals, The American Ceramic Society, Westerville, OH, 1990.

7. W.H. Gitzen, Alumina as a Ceramic Material, The American Ceramic Society, Westerville, $\mathrm{OH}, 1970$ 